\title{
Families in Critical Care Settings: \\ Where Fear Leads to Silence
}

\author{
Marlene Zichi Cohen \\ Martha J. Craft \\ and \\ Marita Titler \\ University of Iowa
}

Sarah Hargrove ${ }^{1}$ is a 40 -year-old grocery store clerk who has had asthma for a number of years. This attack, the most severe she has ever had, began with a viral infection which progressed until she had so much difficulty breathing that her husband took her to the emergency room of a small local hospital. The local hospital admitted her but later decided to transport her by helicopter to a large teaching hospital 60 miles away.

Sarah's husband Jack is a 42-year-old farmer. He is a large, quiet man who told us seeing his wife in the intensive care unit "don't bother me too much."

Don is Sarah and Jack's youngest child. He is 11 years old and said, "it is just not the same around the house without" his mother. We did not speak with his 15-year-old or 21-year-old brothers.

Karen is a 25-year-old nurse who cared for Mrs. Hargrove in the intensive care unit. She has had three years of nursing experience, two of those in critical care settings.

Each of these people describes a different experience. We explored these experiences in a study designed to better understand the impact of critical care hospitalization.

\section{A Portrait of the Family}

Mrs. Hargrove told us:

I was extremely scared. You did not really know what was happening except that I did not feel right. But I had a lot of faith that they were going to make it so I could breathe. This was my biggest thing-not being able to breathe. And I thought I was dying, I really did. I was very scared.... I remember begging them for help and them telling me they were doing everything that 
they could. I remember being told to breathe and that was scary because I thought I was breathing.... It was really scary.... I did not like having the tubes put in-I don't remember all that but they told me I had to have it and I fought them. I remember one guy coming at me at the very end and holding my hands back because I was not going to have one more tube shoved down there. But I did.... I did not want them [some things] done, but they told me I had to have them done.

Despite having had asthma attacks many times before, Sarah had no way of gauging the severity of the attack. She knew she had been transferred to the teaching hospital and saw this as a sure sign of relief. She had to cope with being terrified, begging for help, and then being violated as the intubation ${ }^{2}$ procedure caused even more discomfort and was done despite her struggles.

\section{She described her family's reaction:}

Just really seeing faces-it was very traumatic. They came in and would look down at me and I would see fear. That is very emotional-it is very hard to talk about. I remember my sister looking at me and she was so scared. I thought, "Hey, I am the one that is supposed to be scared," and it made me feel good. But it scared me because I did not want to leave them, and I was afraid I was. I did not realize this was so scary to me till now. I think it is good that we're talking about it now, because I did not sleep very good last night ... when it comes to you knowing you almost died - and so many people depend on you ... every day gives you a big feeling of responsibility that you did not have. I was worried about my kids for support. I thought they would al ways have good physical care because their daddy would always be there, but that emotional side. As when you [the interviewer] came in, I thought support-if I don't make it, this lady can do something or somebody down the line from her will help my family if I do not make it. And Jack [husband], I did not realize-it sometimes takes things like this to wake you up-how much I meant to him, because he does not say but he has been pretty scared.... The night I came up here he was at a basketball game and he did not know anything about it until he read the note on the refrigerator door [which their son had left when the hospital called]. He said he almost went wild. He did not know what to do. He did not know whether to call the doctor or come here. The girl that I work with called me today and she said he was just a basket case-he did not know what to do. Now he tells me that he loves me and it means a lot.... You knew it was there but you get so wrapped up in your job and being a mommy and all this, I guess you just don't take the time. I thought about that a lot. 
And I can see him standing there holding my hand and he says, "Don't leave me like this." I think that will always stand out in my mind. I may be able to walk out the door but not leave him like this.

Her sense that she was dying, manifest first in her inability to breathe, was confirmed in the faces of her family. Their fear reinforced her own thoughts and concerns about leaving her family. The aftermath of the shock, the what ifs continued to concern her after she was assured that she would not die from this attack. Her husband's request "not to be left" has become both a confirmation of this need for her and another burden, as if she were able to control these attacks. There is also the potential there in that "walking out" was possible but dying was not.

\section{About her children Sarah said:}

I don't think they comprehended it. They were told I had tubes in and that I could not talk to them on the phone. I don't think they can visualize in their mind what it was really like.... Don [the youngest] has been up here and he just stands and looks at me to make sure I am really alive, I guess. Pinching me and all this.... The other one sits, they just both sit and stare at me just like they-I guess they are pretty tickled that I am still with them. They don't say too much. If I look at them they grin. They just kind of hang on my hand.

The oldest one, who is at home right now, called and he said, "Hi, Mom." I said, "Hi." He said, "It is me, Rick," like I was not too sure who he was. And I said, "Yeah, how are you doing?" He said, "Well, I am fine, but more important, how are you doing?" I answered, "I feel a lot better." He said, "You sound better" and he just talked about making dinner and cleaning and how he helped his brother. I did not say anything. He said, "Did you hear me?" and I said, "Yeah." He said, "Yeah, I helped my brother." When I thanked him he was real quiet. Then he said, "Well, I think I owe you that much." What stands out in my mind is that he just realized that I was capable of getting sick like anyone else. They thought, "Mommies just don't do these things" and yet it does happen.

Her children confirmed her sense of being close to death and their own need of her. Like her husband, they, too, had not voiced their love and concern for her in their everyday lives.

This picture of a family so overwhelmed by this experience that they cannot talk about it is confirmed by Sarah's husband. When asked to describe what it was like having his wife in the 
intensive care unit, he could hardly respond. After a long pause he said,

It is just-I guese it don't bother me too much. She is being well taken care of, so it ien't too big of a deal now.... Nothing surprised me too much. I suppose it would more if she had been in an accident or something like that, but with what she is taking now-it is a lot like her just being in the hospital other than some more tubes. It is not much different you know. She has been in the hospital before with the same thing but not in critical condition, so there is not a lot of difference really.

When asked how he was affected, he said, "Just concerned. Nothing real fantastic. Just concerned."

About his children he said:

The boys have always been independent. It didn't really bother them that much. One of them cooks. It doesn't bother them too much because they really take care of themselves.... Neither one needs much bother really. The younger one is a little lonely-he is sick-but when he gets well he will be all right. [He had an infection and was taking antibiotics.]

He spoke about learning his wife was transferred from the local hospital to the larger one:

She was in the hospital there and they shipped her per air care.... I had gone out that evening [after she was admitted to the local hospital]. There was a note on the refrigerator from my boy [when I got home]. He had something to tell me about Sarah, not that it was an emergency or anything 80 I didn't wake him up. I didn't know about it till the next morning. And that is about all that went on.... It was nothing real serious but they couldn't handle it at home.

He talked about what this was like for his wife: "I knew she was scared-real scared for the first couple days. Concerned. I haven't really talked to her because she has to write everything and I have not had that much information from her really."

Don, their 11-year-old son, told us:

[The intensive care unit] it was OK. It was pretty OK. [The worst part was] just hearing about the bad things that dad says have been happening to her. [For example,] the stuff going up her nose and going into her lungs and stomach.... Plus having her gone.... I just want to hope that she gets much better.

When asked about changes in his life, Don said, "Well, our house is not as clean as it used to be. It is just not the same around the house without her. I just mainly miss her." 
When asked about his father, he said, "He is kind of worried ..., because he is just really worried about mom."

Interviewer: "How do you know he is worried?"

Don: "Well, he kind of tells a lot of stories about her, about how she has been. Been acting kind of funny."

Interviewer: "How has he been acting kind of funny?"

Don: "Well, he has been staying up later than usual. He usually goes to bed about 8:30 and now he kind of stays up late. $\mathrm{He}$ stays up till about 9:30 or 10:00."

Don told us his brother was "kind of worried about her ... he keeps asking questions about her ... [but he] probably is not as worried as much as I am. I am mom's main kid."

The father has been the link between Sarah and the children. They know that things are not easy for Sarah because Dad had "related all the bad stuff." Yet he, too, found it impossible to talk with Sarah about her real feelings because he had to communicate with her through writing. How does one talk to a person who is "real scared" about dying when you have to write down your own feelings, put them as marks on paper, and when you are unable to voice your own concerns, give your own anxieties. How do you talk to your children about their worries?

The nurse, Karen, gives a different picture:

I did not get the impression that she was overwhelmed by the experience. She seemed very cooperative and was appropriate as far as being alert, following requests. She always looked relaxed, I think. I did not have the opportunity to speak with her because she was intubated while I took care of her.... Whenever some procedure was going to be done or, for instance, when she was going to be suctioned, she appreciated being told what was going to happen, and what was expected of her and what, maybe, she experienced. She always seemed to nod in understanding.... I can't remember having difficulty doing any procedure with her because she was always cooperative. That helped.

Karen sought cooperation from Sarah. It "helped" in doing procedures. It helped to make the task easier and perhaps also helped to confirm for Karen that Sarah was benefiting from her help and was grateful. The explanation of the procedure was the only story. When Sarah cooperated she and the procedure became one. If Sarah had wanted to assert her self she would have had to fight, to be difficult, to withdraw from the very procedure she knew was necessary to sustain her. 
I met her husband while she was still in isolation. I explained to him that he needed to wear a mask in the room but he had already done it so he was pretty familiar with the procedure. [Mrs. Hargrove was isolated until the virus causing her condition was identified.] He didn't really ask too many questiono-how she was doing, what was going to happen today. He would always leave the room whenever I went in so I did not have much contact with him. He did not appear uneasy at all or that concerned or anything - but he seemed to me, I don't want to say reluctant, but just real aware of the space we needed. He was very cooperative with leaving.... It is hard for me to remember if he felt like he was in the way or if he was just being considerate... I did not have any contact with the family and the husband did not really offer any information as to how they were dealing with the situation. Mrs. Hargrove, like I said, could not talk, she was not able to give much information. Frankly, I don't know [how this affected the family].... Her husband did not seem real concerned about any problems.

Karen's focus on Sarah meant that her discussion with Sarah's husband concerned the importance of following procedures, but she did sense from his physical actions that he was distancing himself from the situation. Although Sarah was intubated and unable to speak, Karen had no need of information from her family and hence would have answered questions, but asked none.

\section{The Silences of Hospitalization}

Genuine dialogue is difficult in intensive care settings. It is often limited because some of the patients have short stays or some of the nurses choose to limit their contact or take a break from caring for long-term patients. Our task of finding a nurse who knew the patients and families well enough to be interviewed for our research was often difficult. As this nurse indicated, it is easy for the nurses to focus on the patient but not the family. Karen did not seem to feel a need to assess the husband's state. He did not offer information and she did not think to ask. Perhaps she was more concerned about the patient and herself. She reminded us of the power and control staff have when she said she "let" the husband sit with his wife "longer than 10 minutes every hour because, as I said, he was very considerate about leaving right away if we came into the room, but I think it was important to him to stay in there with her." These patients are mentally and emotionally demanding, and the nurses sometimes need to distance themselves. Indeed, we experienced the stress of hearing the dramatic and often 
tragic stories people had to tell. This is a project none of us can work on for too many hours without a break.

The nurses may require supports that are not now available to them to maintain awareness of the anxiety the patient and family experience while they perform the physical care required for the patient's survival. Some of the nurses expressed feelings of frustration because they themselves needed to stay with the patient, and yet they knew that there was no one free to interact with the family. The intensity of the physical care and technology does not always permit discussion with family while the nurse works with the patient. There are so many complicated procedures that require the nurses' full concentration that discussion may be limited.

Paterson and Zderad (1976) discussed the amount of presence with others that nurses must have to establish relationships and understanding through authentic dialogue:

It goes without saying that it would be humanly impossible for a nurse to be wholly present to numerous patients for eight hours a day.... To offer genuine presence to others, a belief must exist within a person that such presence is of value and makes a difference in the situation. (pp. 15, 6)

Karen spoke about being helpful-the helpful patient who cooperated in the procedures, the helpful husband who left the nurse to work alone and did not ply her with questions while she attended to the patient. Her definition of helpfulness was narrow: Its major focus was the physical care of the patient from the nurse's perspective. When asked what might not have been helpful for the patient or the family, she paused: "That is a tough one. You spend so much time trying to be helpful.... How did you come up with this question?"

In a different situation, nurses have to reach beyond helpfulness to genuine dialogue. They have to expand their interest to avoid nonhelpfulness as the only response indicative of a patient's concern. While the patients' critical condition and the accompanying technology make heavy demands on the nurses, perhaps a more acute awareness by the nurses of the intense emotions these patients and their families experience would help them value the difference their genuine presence could make.

Communication is further limited by isolation and intubation, two common occurrences in critical care settings. Certain isolation protocols require that everyone wear gowns, gloves, and masks. In addition, staff tend to enter these rooms less 
often and therefore have less contact with patients. Although Mrs. Hargrove was intubated, she wrote notes and seemed to us to be able to communicate. She was alert, oriented, and able to write notes. However, both her husband and the nurse felt they had little information from Mrs. Hargrove because she had to write everything. Although she could communicate in writing, perhaps it was more difficult and took longer to express things other than immediate physical concerns. This more limited communication did not prevent her husband and son from knowing how scared she was. The nurse might have come to better understand how this experience was for these people by attending to facial expressions, body postures, and unspoken questions.

Although Mr. Hargrove's concern is obvious to his wife and son, he was not able to talk about it. One might think that if this is the family's typical pattern, perhaps it is best not to disrupt it. However, these are extraordinary circumstances. Most people find their usual patterns of life disrupted and may need help to cope with or grow from the experiences. As Peplau (1952) said in her classic nursing theory, nurses must listen to patients review events and feelings connected with them. With this full participation, patients will be able to integrate the events into their stream of life experiences. Clarifying the meaning of these experiences is essential for this integration to occur.

Nurses should listen for what is unsaid as much as what is said. They need to carefully observe body language and nonverbal cues. Although Mrs. Hargrove seemed alert and looked relaxed to the nurse, perhaps asking Mrs. Hargrove how she felt would have given the nurse more sympathy for this patient's feelings. Mr. Hargrove told us he was not bothered too much. Perhaps spending more time with him would help him feel freer to discuss his feelings. It might also help let him know that many people in his situation do have strong feelings and that it is often beneficial to talk about them.

Our contact with Mrs. Hargrove confirms the importance of articulating and clarifying perceptions. She wrote us a note one month after our interview and said:

After I left [the hospital] I got sick again five days later and spent eight days in a [different] hospital. I just got out yesterday.... Things have really been hard being sick again and all. My husband even asked me for a divorce because he said he couldn't handle all my sickness after all. I asked him to wait and remember our vows so he agreed to try to work it out. I reminded him 
my illness has been no picnic for me to go through. I just thought you'd be interested with our situation as you seemed so genuinely concerned.

A month after this letter, another arrived:

We have worked through all our problems and things are really going good. We've talked like never before and the whole family is closer. Things like I went through really do have effects, good and bad, on a family.... My kids (all three) are great! They are very supportive and the 15-year-old even talked to his dad about my illness. Only he and my son who flew back from Germany knew of the situation. They both told their dad they'd stay with mom if he really wanted out.

My husband and I are closer than we've been in years. He is supportive, helpful, caring and able to exprese himself like never before. I just wanted you to know as you were so nice to me.

\section{Voicing the Family's Concerns}

Perhaps it helped this family to talk with us about their experiences, although clearly more intervention might have helped them avoid the crisis they experienced. They were finally able to discuss Mrs. Hargrove's illness. Having these discussions may help families have increased comfort in dealing with strong emotions. They may learn that it is normal to cry and that they can cope with their feelings.

The continued contact with Mrs. Hargrove illustrates the power of the experience of critical care hospitalization. This experience cannot be confined to the hospital, and there is tremendous therapeutic value in the nurses' dialogue with patients. These conversations must continue over time until the person can integrate the meaning of the experiences.

It is particularly important that nurses be aware of the feelings these families have and help them to express them. The expression of strong emotions is not always accepted in our culture. Many people are uncomfortable dealing with feelings and need help to express them. As Lear (1980) said in his wife's powerful description of his experiences with cardiac surgery and critical care hospitalization, "I was afraid that if I ever began to cry, I might cry my heart out" (p. 144).

Nurses need to learn to accept these strong emotions and encourage silent people to talk. If nurses are uncomfortable or do not want to take the time to hear about patients' feelings, they will surely communicate this, at least nonverbally. The emphasis on the person, the patient, which is evident in many 
nursing theories in turn places tremendous pressure on nurses in critical care settings. Support for nurses is needed to help them cope with what they hear from these families. Because nurses have to listen to the unspoken concerns of patients, so also must they avoid having to use the surface counseling platitudes of telling others "not to worry" while being overcome with concern themselves.

Nurses also need to have help developing communication skills that can be combined with physical care. Although they may not have the time to spend only talking with patients, if they have an awareness of the importance of learning about people's reactions, they will be better able to incorporate this in their work. Nurses need to consider the family's needs rather than thinking only about their own needs (e.g., "for space").

Parents have also told us that they do not feel competent to talk with their children about what is happening to their other parent. Rather than avoid talking with them, help from a professional to communicate with the child may be indicated. Although parents can communicate facts and events, some may need more help expressing emotions. The parents we spoke to believed their children did not understand what was happening to their parent; the children easily identified the parents' experiences and emotions. Don knew his father and brother were worried and he was also worried. He said, "I was real worried about her [Mom] and not being able to see her. My dad brought me up-now I am not as worried as I was before because I got to see her."

Finally, nurses in critical care settings need to use the many resources that are available to them. Clinical nurse consultants such as clinical specialists in psychiatric-mental health nursing or in child health could be called in more regularly. Perhaps school nurses or counselors should also be called more often to let them know the child is going through a crisis. We provided referral information to most of the 12 families ${ }^{3}$ we spoke with. Some of them had problems which were so profound and longstanding that they required long-term counseling. Others were encouraged to talk with family, friends, and ministers. Still others were referred to the hospital social worker or to support groups which exist for various conditions, for example, alcoholism, cancer, and cardiac conditions. Some units have established ongoing support groups for families of patients in intensive care, having recognized that these persons are at high risk. 
Our informants have expressed the profound effects critical care hospitalization has on each individual in the family. Having a heightened awareness of these effects will allow nurses to assess family needs rather than accepting it when family members leave the room when they enter. Encouraging family members to stay and express their feelings and referring them when extra support is needed will allow nurses to better meet the needs of these people. Reading descriptions of these varying viewpoints will also help nurses remain aware of the needs families have for the authentic presence they can provide.

\section{Notes}

1. All names and identifying information have been altered to maintain informants' anonymity.

2. Intubation involves inserting a tube into the person's airway to provide entrance for air. Mrs. Hargrove's tube was connected to a respirator for mechanical aid in breathing.

3. We interviewed 12 families and a nurse who cared for each of the patients in the intensive care unit. Patients were either in the Medical Intensive Care Unit or in the Coronary Care Unit of a large midwestern teaching hospital. These patients were all extremely ill, required the use of much techology in their care, and their health status was unstable. The outcome of their illness was uncertain. Large numbers of staff members and learners were involved with each patient-interns, residents, fellows, staff physicians, nurses, and a variety of technicians. The only requirements for including families in this study were that they had a child between the ages of five and 18, that they gave their consent, and that the nursing staff agreed that the timing for approaching the family was appropriate.

4. This project was supported in part by the North American Nursing Diagnosis Association.

\section{References}

Lear, M.W. (1980). Heartsounds. New York: Simon and Schuster.

Paterson, J.G., \& Zderad, L.T. (1976). Humanistic nursing. New York: Wiley.

Peplau, H.E. (1952). Interpersonal relations in nursing: A conceptual frame of neference for psychodynamic nursing. New York:

Putnam's. 